treatment but also for an appreciation that disabled people deserved special understanding because of their superior spiritual status. ${ }^{10}$

In a similar revolutionary manner Paracelsus confronted the contemporary craze for seeing witchcraft everywhere and

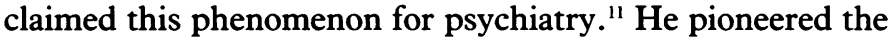
investigation of diseases of mineworkers and in 1520, aged 27 , produced the first monograph ever written on occupational disease. ${ }^{12}$ The longest section of this work dealt with the signs and symptoms of mercury poisoning. This experience laid the foundations for his application of compounds of mercury and other metals for therapeutic purposes. Arguably this advocacy of mercurials for the treatment of syphilis laid the foundations for the success of the paracelsian movement, because the newly arrived scourge of syphilis was the most feared disease of the sixteenth century, occupying a similar position to AIDS in Africa today. The paracelsian mercurials represented one of the small handful of important therapeutic advances made before the present century.

Paracelsus therefore made a significant contribution to medical knowledge across a broad front. He represented a new mood of therapeutic optimism and outlined a scientific approach capable of giving reality to his ambitious aspirations. The new science was guided by his conviction that the "light of nature" endowed the human race with the capacity to attain dominion over nature and, indeed, command over the stars. The twentieth century has witnessed the realisation of these objectives, perhaps even beyond the horizons of Paracelsus's fertile imagination.
Despite all its achievements, modern medicine has failed to capture Paracelsus's sensitivity to the environmental, social, spiritual, and moral dimensions of medical intervention. This outlook was a consequence of his exploitation of the neoplatonic belief of the analogy between the macrocosm and microcosm and his belief that humans were linked with God and nature in a dynamic cosmic order. Modern scientific medicine has of course dispensed with such speculative constructs, but thereby it may also have sacrificed therapeutic insights available to our renaissance predecessors. In this respect orthodox medicine may have placed itself at some disadvantage to its complementary counterparts.

CHARLES WEBSTER Senior Research Fellow

All Souls College,

Oxford OX1 4AL

1 BMA's 150th anniversary council dinner. $B M \mathcal{F} 1983 ; 286: 65$.

2 Alternative medicine [editorial]. $B M \mathcal{H}$ 1983;287:307.

3 BMA. Alternative medicine. London: BMA, 1986.

BMA. Complementary medicine. The BMA guide to good practice. Oxford: Oxford University Press (in press).

Webster C. The great instauration: science, medicine and reform 1626-1660. London: Duckworth 1975 .

6 Webster C. From Paracelsus to Newton: magic and the making of modern science. Cambridge: Cambridge University Press, 1982.

Pagel W. Paracelsus: an introduction to philosophical medicine in the era of the renaissance. Basle: Karger, 1958.

8 Goldammer K. Paracelsus in neuen Horizonten. Vienna: Verband der Wissenschaftlichen Gesellschaften Österreichs, 1986.

schaften Osterreichs, 1986.
Goldammer K. Der Götlliche Magier und die magierin Natur. Stuttgart: Franz Steiner, 1991.

9 Goldammer K. Der Götliche Magier und die magierin Natur. Stuttgart: Franz Steiner, 1991 .
10 Cranefield PF, Federn W. The begetting of fools: an annotated translation of Paracelsus' De generatione stultorum. Bulletin of the History of Medicine 1967;41:56-74, 161-74.
gention

11 Galdstone I. The psychiatry of Paracelsus. Bulletin of the History of Medicine 1950;24:205-18.

12 Rosner E. Hohenheim's Bergsucht monographie. In: Dilg-Frank R, ed. Kreatur und Kosmos. Internationale Beitrage zur Paracelsus Forschung. Stuttgart: Gustav Fischer, 1981:20-52.

\title{
Hypertension and cancer
}

\section{Correlation or coincidence?}

Two papers by Fletcher et al (p 622) and Hole et al (p 609) in this week's journal constitute the latest chapter in the slowly unfolding chronicle on hypertension and cancer. Persuasive evidence linking these two conditions first surfaced in $1975,{ }^{3}$ but nearly two decades later their association remains enigmatic.

Given the serious clinical ramifications, most attention has been justifiably directed at determining whether antihypertensive treatments are carcinogenic. Firstly, retrospective studies implicated reserpine in breast cancer, but the drug was later absolved by prospective analyses. ${ }^{34}$ Similarly, limited case-control data suggested an association between use of diuretics and renal cancer, but larger series and the outcomes of randomised clinical trials have not confirmed this. ${ }^{56}$

More recently, the accusing finger has shifted to the $\beta$ blocker atenolol. The Medical Research Council's trial of antihypertensive treatment in elderly people found that death from cancer was nearly twice as common in men receiving atenolol as in men receiving placebo. ${ }^{5}$ This association was not observed in women, and because it was noted in an unplanned subgroup analysis the authors urged that the finding should be interpreted cautiously.

Against this backdrop come this week's studies of hypertension, antihypertensive drugs, and cancer. Both reports constitute post hoc analyses of data on several thousand patients followed up for varying periods at regional hypertension clinics. Cancer rates according to type of antihypertensive treatment are reported, with particular attention being paid to atenolol. Both groups of investigators adjust for age, sex, and current smoking habit, although without more thorough consideration of known risk factors for cancer (for example, past smoking habit, use of alcohol, and occupational exposures), the validity of the results remains in some doubt.

Fletcher and colleagues report that patients receiving atenolol have the same mortality from cancer as those not receiving atenolol.' ${ }^{1}$ Diuretics are also not associated with cancer. Hole and colleagues report the incidence of cancer as well as mortality, and they compare rates observed in hypertensive patients with normative data on incidence from national figures and from a survey in Renfrew and Paisley. ${ }^{6 a}$ Although their abstract states that neither men nor women taking atenolol experienced an increased rate of cancer, subgroup analysis shows that non-smoking men receiving atenolol had a significantly increased risk of dying of cancer (relative risk 1.58). Though this again represents an unexpected finding on subgroup analysis, more than three quarters of men in the Medical Research Council's trial were non-smokers, and one could argue that both studies observed increased cancer mortality in non-smoking men treated with atenolol. Other large clinical trials have not described any increase in cancer after treatment with other $\beta$ blockers, but reporting of such unanticipated outcomes is often incomplete.

Both of the new studies replicate the previously reported association between renal cancer and hypertension. The small number of cases, however, precludes examination of the effects of different antihypertensive drugs, which is important because some epidemiological evidence suggests that the increased rate of renal cancer in hypertensive patients is attributable, at least in part, to their use. ${ }^{78}$ 
Irrespective of any effects of antihypertensive drugs, systolic blood pressure itself correlates with risk of cancer. ${ }^{39}$ Though an increased incidence of cancer could be due to ascertainment bias because hypertensive patients are under closer medical surveillance than normotensive patients, this would not account for the association between mortality from cancer and blood pressure. ${ }^{310}$ Instead, it is typically hypothesised that this association is attributable to other confounding factors. For example, salt intake contributes to hypertension and is implicated as a causal factor in gastric cancer. Here, the concomitant decreases in salt intake, gastric cancer, and hypertensive cardiovascular disease during the twentieth century in most industrialised countries are noteworthy but fall short of establishing causality. ${ }^{11}$ Analogously, heavy alcohol consumption contributes to both increased blood pressure and many malignancies. ${ }^{12}$

A powerful risk factor for hypertension is obesity. Because increased consumption of fat results in an increase in both weight and blood pressure and has also been implicated as a risk factor for some forms of cancer, dietary fat may explain the correlation between blood pressure and cancer. ${ }^{613}$ Similarly, low socioeconomic status simultaneously confers an increased risk of high blood pressure, certain cancers, and exposure to known carcinogens (for example, alcohol and tobacco). Nonetheless, no epidemiological study has yet shown (by multivariate analysis) that one or more of these hypothesised mechanisms truly accounts for the association between high blood pressure and cancer.

Lingering concerns therefore remain about the potential contribution of hypertension and its treatment to the incidence of cancer. Any increase in cancer with a particular antihypertensive drug will be difficult to detect because of both the dearth of large scale clinical trials which directly compare different treatments and the relative infrequency of cancer in prospective studies. Still, such evaluation is important because, for example, if the incidence of cardiovascular complications of hypertension is $5 / 1000 /$ year and if a drug reduces risk by $30 \%$ (that is, by $1 \cdot 5 / 1000 /$ year) then with an increase in cases of cancer of just 2/1000/year a particular drug could do more harm than good. It becomes important, therefore, that any new antihypertensive drug should be compared with other agents in clinical trials that are large enough to detect infrequent adverse morbid events. With respect to first line treatment with diuretics and $\beta$ blockers, consolation is available in the fact that meta-analysis of large, randomised clinical trials have not identified any increase in deaths from cancer and the use of these drugs seems to reduce total, as well as cardiovascular, mortality. ${ }^{14}$

Preparation of this manuscript was supported in part by HL46328 and HL40962, United States National Institutes of Health

MATTHEW F MULDOON Assistant professor of medicine

Center for Clinical Pharmacology,

University of Pittsburgh,

Pittsburgh,

PA 15260, USA

LEWIS H KULLER

Professor of epidemiology

Graduate School of Public Health,

University of Pittsburgh

1 Fletcher AE, Beevers DG, Bulpitt CJ, Coles EC, Dollery CT, Ledingham JG, et al. Cancer mortality and atenolol treatment. BMF 1993;306:622-3.

Hole DJ, Hawthorne VM, Isles CG, McGhee SM, Robertson JWK, Gillis CR, et al. Incidence of and mortality from cancer in hypertensive patients. $B M J$ 1993;306:609-11.

3 Dyer AR, Stamler J, Berkson DM, Lindberg HA, Stevens E. High blood-pressure: a risk factor for cancer mortality? Lancet 1975 ; i: 1051-6.

4 Curb JD, Hardy RJ, Labarthe DR, Borhani NO, Taylor JO. Reserpine and breast cancer in the hypertension detection and follow-up program. Hypertension 1982;4:307-11.

Medical Research Council Working Party. Medical Research Council trial of treatment of hypertension in older adults: principal results. BMf 1992;304:405-12.

hypertension in older adults: principal results. BMF 1992;304:405-12.
6 McCredie M, Stewart JH. Risk factors for kidney cancer in New South Wales, Australia. II. Urologic disease, hypertension, obesity, and hormonal factors. Cancer Causes and Control 1992;3: 323-31.

6a Gillis CR, Hole DJ, Hawthorne VM. Cigarette smoking and male lung cancer in an area of very high incidence. II. Report of a general population cohort study in the West of Scotland. f Epidemiol Community Health 1988;42:44-8.

7 Fraser GE, Phillips RL, Beeson WL. Hypertension, antihypertensive medication and risk of renal carcinoma in California Seventh-Day Adventists. Int $\mathcal{F}$ E pidemiol 1990;19:832-8.

8 Grove JS, Nomura A, Severson RK, Stemmermann GN. The association of blood pressure with cancer incidence in a prospective study. Am $\mathcal{F}$ Epidemiol 1991;134:942-7.

9 Goldbourt U, Holtman E, Yaari S, Cohen L, Katz L, Neufeld HN. Elevated systolic blood pressure as a predictor of long-term cancer mortality: analysis by site and histologic subtype in 10000 middle-aged and elderly men. JNCI 1986;77:633-70.

10 Farchi G, Menotti A, Conti S. Coronary risk factors and survival probability from coronary and other causes of death. Am $\mathcal{F}$ Epidemiol 1987;126:400-8.

11 Whelton PK, Goldblatt P. An investigation of the relationship between stomach cancer and celton PK, Goldblatt P. An investigation of the relationsh
cerebrovalar disease. Am $\mathcal{F}$ Epidemiol 1982;115:418-27.

12 Raynor WJ, Shekelle RB, Rossof AH, Maliza C, Paul O. High blood pressure and 17-year cancer mortality in the western electric health study. Am $\mathcal{F}$ Epidemiol 1981;113:371-7.

13 Yu MC, Mack RM, Hanisch R, Cicioni C, Henderson BE. Cigarette smoking, obesity, diuretic use, and coffee consumption as risk factors for renal cell carcinoma. INCI 1986;77:351-6.

14 Collins R, Peto R, MacMahon S, Hebert P, Fiebach NH, Eberlein KA, et al. Blood pressure, stroke, and coronary heart disease. Lancet 1991;335:827-38.

\section{Diabetic care in general practice}

\section{Adding quality to quantity}

Treating eye, kidney, and foot lesions early in diabetic patients can prevent blindness, renal failure, and amputation, ${ }^{1}$ and the sheer number of patients who would benefit from early diagnosis means that general practitioners have to play a part. Early papers on the topic showed that effective surveillance depends on an up to date register, a recall system, and a simple checklist, ${ }^{23}$ and many primary care teams are now grappling with Tudor Hart's challenge of "doing simple things well, for large numbers of people, few of whom feel sick." ${ }^{4}$

Some teams have made great progress: if well organised they can screen diabetic patients at least as well as outpatient clinics. ${ }^{5}$ Moreover, several different approaches have been found to be effective, including all day clinics, ${ }^{6}$ nurse coordinated care, ${ }^{7}$ and miniclinics. ${ }^{3}$ But what of practices that still do not have the infrastructure or confidence to offer diabetic surveillance?

On page 624 Hurwitz and colleagues report on a prompting

system for diabetes surveillance independent of practices themselves. ${ }^{8}$ This development meets the needs of local practitioners for support in personal education, patient recall, and retinal screening; flexibly integrates generalist with specialist care; and, perhaps best of all, puts patients first by sending the prompt directly to them. The evaluation shows that two thirds of surveillance activity shifted from hospital clinics to primary care, with more effective coverage in the prompted group than in the control group and acceptance levels well above $80 \%$.

Although these findings are encouraging, only people regularly attending diabetic outpatient clinics were studied and only half of those eligible took part. Nor is it clear how much health gain resulted from this screening programme. Surveillance may be carried out adequately by a skilled practitioner in 10 to 14 minutes once or twice a year, but, to have any impact, discussions about management and lifestyle to reduce the risk of complications will take longer. 